\title{
Acquired Reactive Perforating Collagenosis: A Case Report
}

\author{
Madiha Eljazouly $^{1}$, Maha Alj $^{1}$, Fatimazahra Chahboun ${ }^{1}$, Hafsa Chahdi ${ }^{2,3}$, Soumiya Chiheb ${ }^{1,4}$ \\ 1. Dermatology, Cheikh Khalifa International University Hospital, Mohammed VI University of Health Sciences, \\ Casablanca, MAR 2. Pathology, Cheikh Khalifa International University Hospital, Mohammed VI University of Health \\ Sciences, Casablanca, MAR 3. Pathology, Military Hospital Mohammed V, Rabat, MAR 4. Dermatology, Ibn Rochd \\ University Hospital, Casablanca, MAR
}

Corresponding author: Madiha Eljazouly, madihajazouly1@gmail.com

\section{Abstract}

Reactive perforating collagenosis (RPC) is a rare form of dermatosis. It forms with perforating folliculitis, Kyrle's disease, and serpiginous perforating elastosis, which is a group of perforating dermatosis. RPC can be hereditary with autosomal dominant transmission or it can be acquired, which is usually observed in diabetics with chronic renal failure. Here we report a new observation in a 72-year-old woman treated by phototherapy with a favorable outcome

Categories: Dermatology, Internal Medicine, Nephrology

Keywords: perforating dermatosis, familial reactive perforating collagenosis, acquired perforating collagenosis

\section{Introduction}

Reactive perforating collagenosis (RPC) is a rare form of dermatosis. It was first described in 1967 by Mehregan et al. [1]. It forms with perforating folliculitis, Kyrle's disease, and serpiginous perforating elastosis (EPS), which is a group of perforating dermatosis. It is important to underline the association of these various disorders with many diseases as EPS is associated with pseudoxanthoma elasticum, Down syndrome, osteogenesis imperfecta, Ehlers-Danlos syndrome, Rothmund-Thomson syndrome, Marfan syndrome, and the use of D-penicillamine [2]. RPC can be hereditary with autosomal dominant transmission or it can be acquired, which is commonly associated with diabetes and chronic kidney disease. We report a new observation that illustrates the clinical, pathologic, and histochemical features of acquired RPC (ARPC).

Review began 02/13/2021 Review ended 02/22/2021 Published 02/27/2021

(c) Copyright 2021

Eljazouly et al. This is an open access article distributed under the terms of the Creative Commons Attribution License CC-BY 4.0., which permits unrestricted use, distribution, and reproduction in any medium, provided the original author and source are credited.

\section{Case Presentation}

A 72-year-old patient, followed for non-insulin-dependent diabetes with chronic renal failure, presented with generalized chronic pruritus with a very itchy skin lesion that had been evolving for six months and was initially located on the limbs with extension to the back and trunk but sparing the face (Figures $1 \mathrm{~A}, 1 \mathrm{~B}$ ). The clinical examination revealed multiple papulonodular lesions with central umbilicated necrosis and keratinous plug (Figure 2A) associated with pustular lesions and excoriated pigmented atrophic scars (Figure $2 B$ ). Histopathology showed degenerated keratin components in the central goblet epidermis (Figure 3). Masson's trichrome staining revealed altered collagen fibers (Figure 4). Peripheral blood cell count and biochemical examination showed an inflammatory syndrome with anemia at $9 \mathrm{~g} / \mathrm{L}$ serum phosphorus at 58 $\mathrm{mg} / \mathrm{L}$. Hepatitis C virus antibodies and thyroid function tests were normal. The ultrasonic examination was normal. The case was diagnosed as ARPC. UVB TL01 phototherapy with dialysis sessions combined with topical corticoids resulted in a regression of pruritus and lesions. 


\section{Cureus}

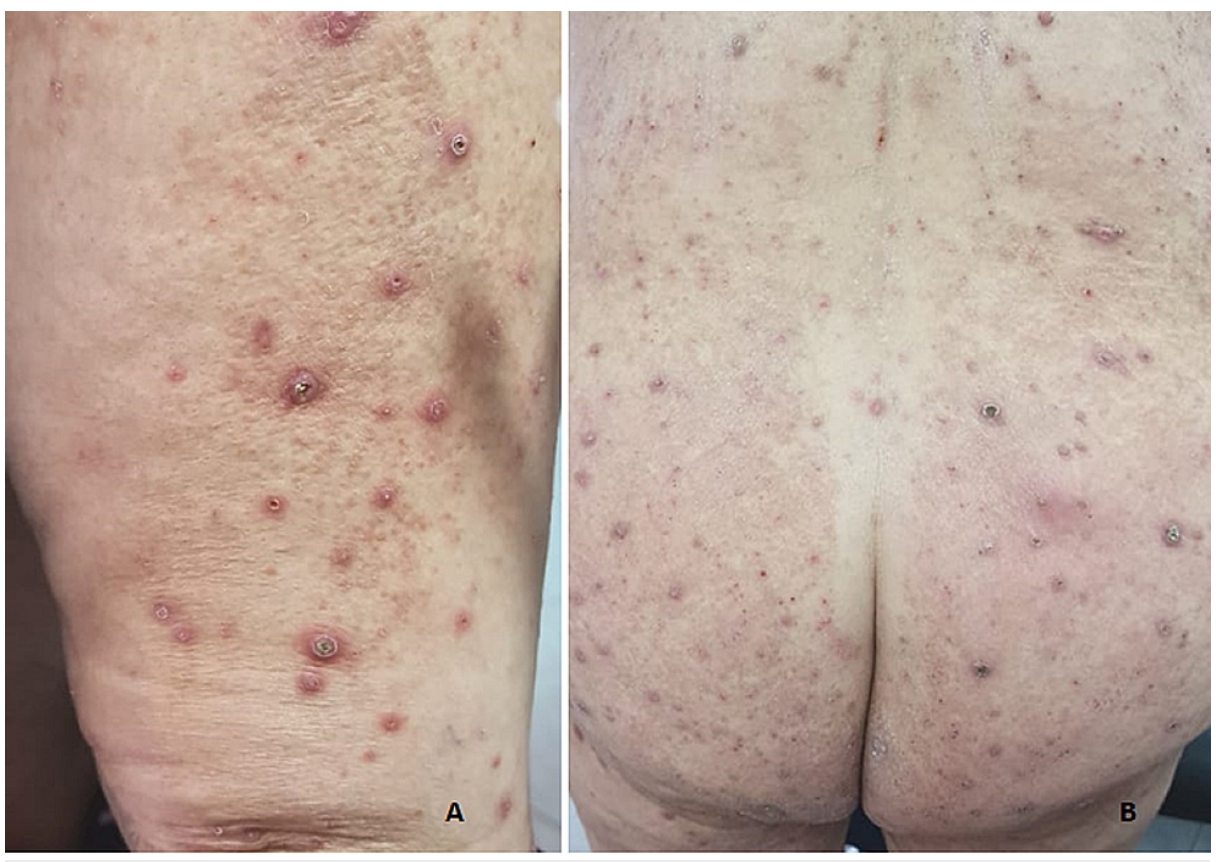

FIGURE 1: Skin lesions primarly located on the limb (A) and extending to the trunk and back surface (B).

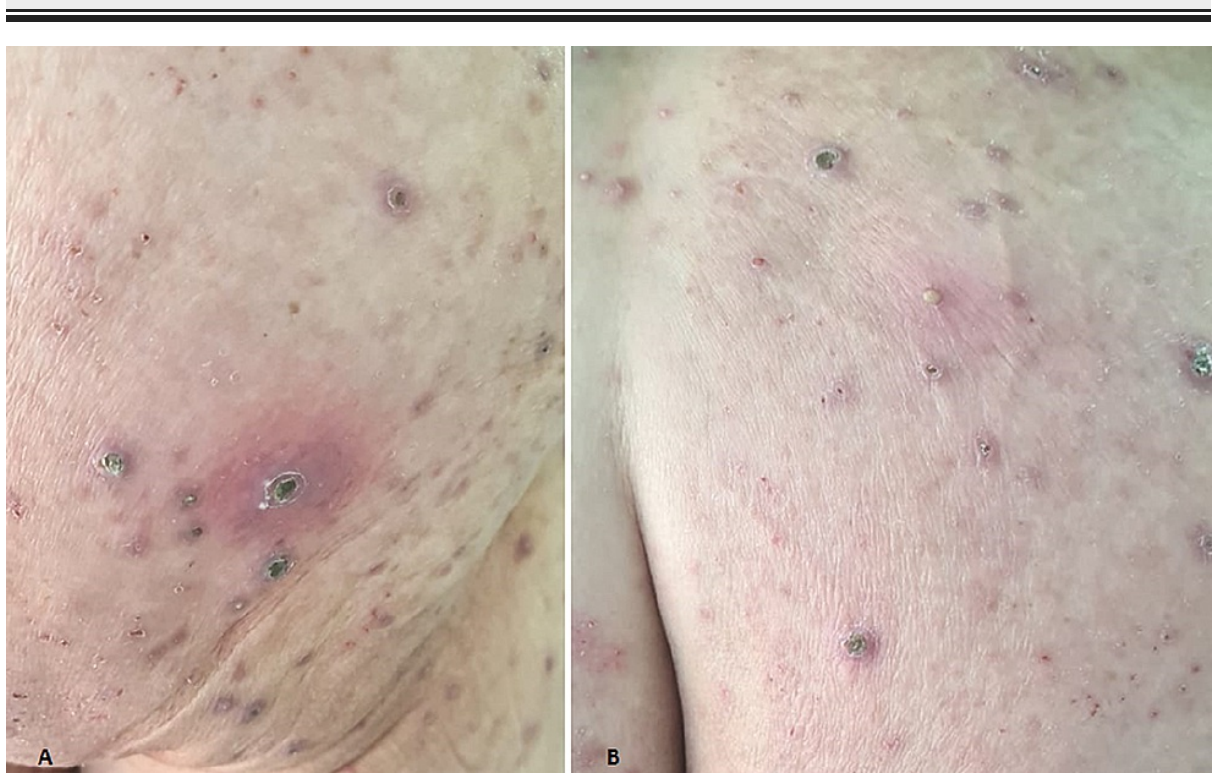

FIGURE 2: Umbilicated papules and nodules with central keratine plug. (A) Inflammatory pustular lesions with brown crusts and dark scars (B). 


\section{Cureus}

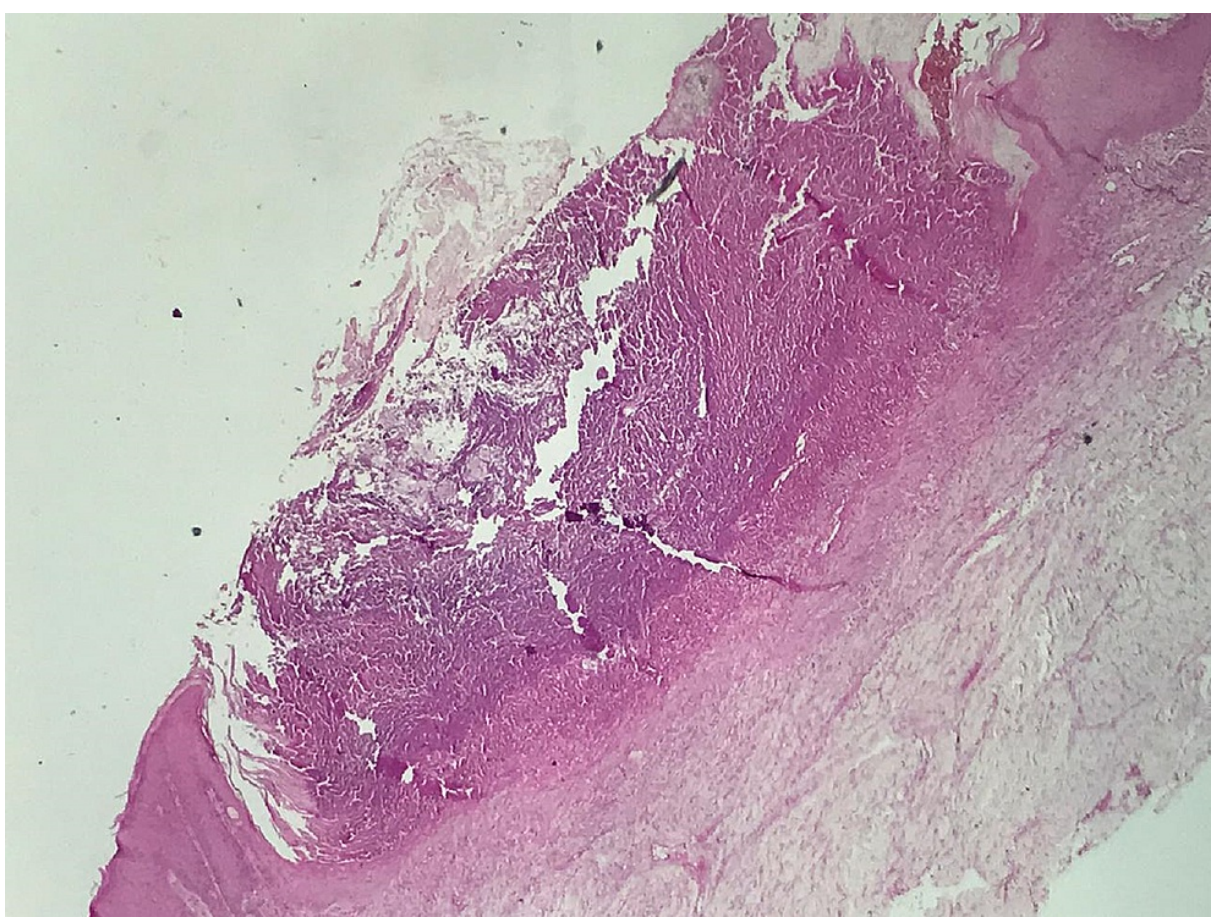

FIGURE 3: Crateriform epidermal ulceration with acanthosis filled with nuclear debris, keratin, and inflammatory cells (hematoxylin and eosin $\times 25)$.

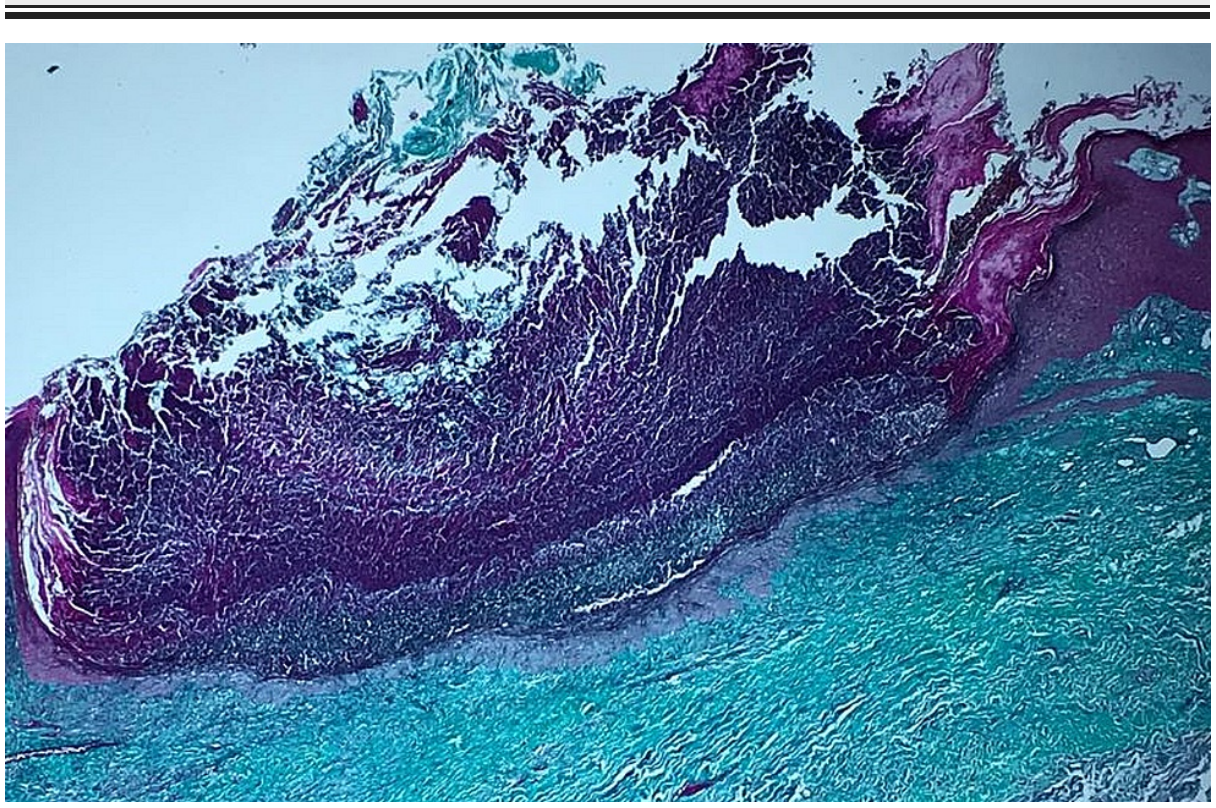

FIGURE 4: Altered collagen in oblique strands indicating transepidermal elimination (Masson's trichrome staining $\times 25$ ).

\section{Discussion}

Perforating dermatosis is defined by the transepidermal removal of components of the dermis, in particular collagen and/or elastic fibers. RPC is caused by the removal of damaged collagen fibers. Its hereditary form is characterized by an early onset in childhood or can occur late in childhood at trauma sites, particularly in the arms and hands [3]. The affection can evolve throughout life, with remissions, especially in summer. Family cases are classically reported [4]. Its acquired type occurring in adulthood is the most frequently described form in the literature. It occurs mainly in cases of renal failure and diabetics patients and is more rarely associated with solid tumors, AIDS, lymphomas, and Hodgkin's disease [5]. Sporadic cases have been 
reported with systemic lupus erythematosus, dermatomyositis, and during treatment with erlotinib [6,7]. However, it should be pointed that some cases of dermatosis can occasionally take on a perforating appearance clinically or histologically, such as keratoacanthoma, foreign body granuloma, amyloidosis, and lichen nitidus. Patterson et al. have identified and classified all of these conditions as atypical perforating dermatosis [8]. For this reason, it is currently recommended that the cases observed in diabetics and renal failure patients be classified as acquired perforating dermatosis (APC) rather than as ARPC [9]. Although the mechanism of atypical perforating dermatosis remains unknown, several authors suggest the role of scratching secondary to pruritus and repeated micro-traumatisms in the triggering of ARPC associated with Hodgkin's lymphoma, solid tumors, thyroid and parathyroid pathology, or infections such as AIDS [10]. In diabetic patients, the abnormal glycation observed after long-term hyperglycemia is the cause of the altered collagen I and III [11]. The diagnosis of ARPC is anatomoclinical. It is commonly manifested by umbilicated papular lesions eventually, and follicular and hyperkeratotic in general. Almost always the lesions are pruritic, and new lesions appear followed by Koebner's phenomenon. In our patient, a clinical polymorphism between APC and perforating folliculitis was observed, suggesting the possible overlap of perforating dermatosis, which is reported in the literature particularly in patients with chronic renal failure [12,13]. The histological study combined with Masson's trichrome stain shows a dome-shaped lesion with a central crater, focal epidermal ulceration, covered by a hyperkeratotic crust, and penetration of underlying dermal tissues through the dermoepidermal junction. Once again, the overlap noted clinically was also raised histologically by Indian authors with the coexistence of the histological image of ARPC and perforating folliculitis $[2,13]$. Dermoscopy findings can also contribute to the diagnosis and reveal a red-brown structureless area covered with crusts and scales centrally, surrounded by a white rim, and a reddish inflammatory circle with peripheral vessels $[12,14]$. The treatment of perforating dermatoses is difficult. There is currently no consensus on treatment. Several therapeutic options have been reported as first-line therapy in ARPC, including topical corticoids, local and systemic retinoids, and UVB-TL01 phototherapy with variable results. Dynamic phototherapy, amitriptyline, and doxycycline have also been the subject of publications [15-17]. Our patient was successfully treated with a combination of UVB phototherapy and dialysis session.

\section{Conclusions}

ARPC is an understood nosological entity, which is frequently accompanied by several systemic diseases including malignant conditions. Thus, thorough paraclinical exploration is necessary to reveal a possible underlying extracutaneous disease.

\section{Additional Information \\ Disclosures}

Human subjects: Consent was obtained or waived by all participants in this study. Conflicts of interest: In compliance with the ICMJE uniform disclosure form, all authors declare the following: Payment/services info: All authors have declared that no financial support was received from any organization for the submitted work. Financial relationships: All authors have declared that they have no financial relationships at present or within the previous three years with any organizations that might have an interest in the submitted work. Other relationships: All authors have declared that there are no other relationships or activities that could appear to have influenced the submitted work.

\section{References}

1. Mehregan AH, Schwartz OD, Livingood CS: Reactive perforating collagenosis. Arch Dermatol. 1967, 96:27782.

2. Atzori L, Pinna AL, Pau M, Aste N: D-penicillamine elastosis perforans serpiginosa: description of two cases and review of the literature. Dermatol Online J. 2011, 15:3.

3. Ramesh V, Sood N, Kubba A, Singh B, Makkar R: Familial reactive perforating collagenosis: a clinical, histopathological study of 10 cases. J Eur Acad Dermatol Venereol. 2007, 21:766-70. 10.1111/j.14683083.2006.02085.x

4. Kanan MW: Familial reactive perforating collagenosis and intolerance to cold . Br J Dermatol. 1974, 91:40514. 10.1111/j.1365-2133.1974.tb13078.x

5. Faver IR, Daoud MS, Su WP: Acquired reactive perforating collagenosis: report of six cases and review of the literature. J Am Acad Dermatol. 1994, 30:575-80. 10.1016/s0190-9622(94)70065-6

6. Ohashi T, Yamamoto T: Acquired reactive perforating collagenosis associated with systemic lupus erythematosus. J Dermatol. 2016, 43:1097-9. 10.1111/1346-8138.13357

7. Suzuki Y, Yamamoto T: Reactive perforating collagenosis during erlotinib therapy. Acta Derm Venereol. 2012, 92:216-7. 10.2340/00015555-1248

8. Patterson JW: Progress in the perforating dermatoses. Arch Dermatol. 1989, 125:1121-3.

9. Salhi A, Heid E, Grosshans E, Cribier B: Collagénose perforante réactionnelle [Reactive perforating collagenosis]. Ann Dermatol Venereol. 2012, 139:481-5. 10.1016/j.annder.2012.04.156

10. Karpouzis A, Giatromanolaki A, Sivridis E, Kouskoukis C: Acquired reactive perforating collagenosis: current status. J Dermatol. 2010, 37:585-92. 10.1111/j.1346-8138.2010.00918.x

11. Fujimoto E, Kobayashi T, Fujimoto N, Akiyama M, Tajima S, Nagai R: AGE-modified collagens I and III induce keratinocyte terminal differentiation through AGE receptor CD36: epidermal-dermal interaction in acquired perforating dermatosis. J Invest Dermatol. 2010, 130:405-14. 10.1038/jid.2009.269

12. Wang C, Liu YH, Wang YX, Zhang JZ, Jin J: Acquired reactive perforating collagenosis. Chin Med J (Engl). 


\section{Cureus}

2020, 5:2119-20. 10.1097/CM9.0000000000000906

13. Abdelbaqi-Salhab M, Shalhub S, Morgan MB: A current review of the cutaneous manifestations of renal disease. J Cutan Pathol. 2003, 30:527-38. 10.1034/j.1600-0560.2003.00109.x

14. Ormerod E, Atwan A, Intzedy L, Stone N: Dermoscopy features of acquired reactive perforating collagenosis: a case series. Dermatol Pract Concept. 2018, 31:303-5. 10.5826/dpc.0804a11

15. Brinkmeier T, Schaller J, Herbst RA, Frosch PJ: Successful treatment of acquired reactive perforating collagenosis with doxycycline. Acta Derm Venereol. 2002, 82:393-5. 10.1080/000155502320624249

16. Yong A, Chong WS, Tey HL: Effective treatment of uremic pruritus and acquired perforating dermatosis with amitriptyline. Australas J Dermatol. 2014, 55:54-7. 10.1111/ajd.12026

17. Sezer E, Erkek E: Acquired perforating dermatosis successfully treated with photodynamic therapy . Photodermatol Photoimmunol Photomed. 2012, 28:50-2. 10.1111/j.1600-0781.2011.00634.x 